\title{
Consumo, ganho de peso e análise econômica da terminação de cordeiros em confinamento com dietas contendo diferentes proporções de resíduo úmido de cervejaria
}

\author{
[Feed intake, weight gain and economical analysis of feedlot finished lambs fed diets \\ with different proportions of wet brewery residue] \\ M.A. Brochier ${ }^{1}$, S. Carvalho ${ }^{2 *}$ \\ ${ }^{1}$ Aluna de pós-graduação - Feevale - Novo Hamburgo, RS \\ ${ }^{2}$ Centro Universitário Feevale \\ RS 239, 2755 \\ 93352-000 - Novo Hamburgo, RS
}

\begin{abstract}
RESUMO
Avaliou-se o efeito de dietas contendo diferentes proporções de resíduo úmido de cervejaria sobre o consumo de nutrientes e o ganho de peso de cordeiros terminados em confinamento, e realizou-se uma análise econômica da alimentação oferecida aos animais. Foram utilizados 25 cordeiros, machos, nãocastrados, da raça Texel, distribuídos aleatoriamente em cinco tratamentos compostos por proporções de $0 \%, 25 \%, 50 \%, 75 \%$ e $100 \%$ de substituição do alimento concentrado por resíduo úmido de cervejaria. Verificou-se efeito quadrático sobre os consumos de matéria seca, matéria orgânica, proteína bruta, extrato etéreo (EE) e de fibra em detergente neutro (FDN), e linear decrescente sobre os consumos de carboidratos totais (CHT) e de carboidratos não estruturais (CNE), quando expressos em $\mathrm{kg} / \mathrm{dia}$. Os consumos de EE e de FDN aumentaram linearmente, e os de CNE diminuíram linearmente, quando expressos em porcentagem do peso vivo e em $\mathrm{g} / \mathrm{kg} \mathrm{PV}^{0,75}$. O consumo de energia líquida, o ganho de peso diário e o custo da alimentação diminuíram linearmente com o aumento da proporção de resíduo úmido de cervejaria. Não foi verificado efeito sobre o lucro relacionado à venda dos animais vivos ou à venda das carcaças.
\end{abstract}

Palavras-chave: ovino, confinamento, produção de carne, resíduo de cervejaria

\begin{abstract}
The effect of diets with different proportions of wet brewery residue on the nutrient intake and the weight gain of feedlot lambs in phase of termination were determined. An economic analysis of the food given to the animals was also performed. Twenty-five non-castrated Texel male lambs were randomly allotted into five groups, consisting in the replacement of the concentrate by wet brewery residue; at proportions of $0 \%, 25 \%, 50 \%, 75 \%$, and $100 \%$. The results of the test revealed a quadratic effect on the intake of dry matter (DM), organic matter (OM), crude protein (CP), ether extract (EE), and neutral detergent fiber $(N D F)$; and a linear decreasing effect on intake of total carbohydrate (TCH), and non-structural carbohydrate (NSC), expressed in $\mathrm{kg} /$ day. The intakes of EE and NDF showed a linear increase and NSC intake showed a linear decrease, expressed in percentage of live weight $(\% \mathrm{LW})$ and $\mathrm{g} / \mathrm{kg} \mathrm{LW}{ }^{0.75}$ The consume of net energy (NE), daily weight gain, and feed cost showed a linear decrease with the increase in the proportion of wet brewery residue. It was not verified effect on profits related to the sales of the live animals or the sale of the carcasses.
\end{abstract}

Keywords: feedlot, sheep, meat production, brewery residue

Recebido em 30 de junho de 2008

Aceito em 17 de setembro de 2008

* Autor para correspondência (corresponding author)

E-mail: sergiocarvalho@feevale.br 


\section{INTRODUÇÃO}

A agroindústria destaca-se por gerar resíduos nobres, apresentados sob a forma de bagaços, farelos, polpas, ossos, vísceras, penas e outros. Deve-se salientar que alguns desses resíduos apresentam alta carga poluidora e, se não forem devidamente destinados, podem provocar significativos impactos ambientais.

Os resíduos agroindustriais, gerados com a evolução do agronegócio e o desenvolvimento dos processos de transformação de alimentos, devem ser reaproveitados (Campos et al., 2007; Rogério et al., 2007), pois, além de poder proporcionar uma fonte de renda alternativa às propriedades rurais e às agroindústrias, estarão contribuindo para a preservação do meio ambiente e, dessa forma, para a obtenção de desenvolvimento sustentável. Para Sachs (2005), existe uma grande necessidade de se repensar a produção e a destinação de resíduos agroindustriais, pois estes podem ser novamente inseridos na cadeia produtiva, gerando grandes ganhos para a sociedade.

Conforme Silva Filho et al. (1999), entre as alternativas para o aproveitamento de resíduos agroindustriais, encontra-se o setor de alimentação animal. $\mathrm{O}$ uso de subprodutos agroindustriais na alimentação animal assume papel econômico muito importante, sendo, muitas vezes, responsável pela viabilidade econômica do sistema. Dentre esses, pode-se destacar o resíduo úmido de cervejaria, que é produzido em grande volume e não apresenta problemas com a sazonalidade de sua produção.

Uma alternativa interessante para o aproveitamento do resíduo úmido de cervejaria é a sua utilização na alimentação de cordeiros em sistema de confinamento, objetivando a produção de carne que atenda a demanda do consumidor. Para tanto, tornase necessária a produção de animais jovens (cordeiros) em condições de abate (Pires et al., 2000).

Segundo Oliveira et al. (2002), um dos grandes problemas encontrados no confinamento de ovinos tem sido os altos custos de produção, principalmente no que se refere à alimentação. A utilização de resíduo úmido de cervejaria na terminação de cordeiros confinados tem grande potencial, pois pode levar à redução significativa dos custos de alimentação e, ao mesmo tempo, evitar a ocorrência de impactos ambientais advindos da indústria cervejeira, sem que ocorram quedas nos índices produtivos.
Assim, os objetivos deste trabalho foram avaliar o efeito de dietas contendo diferentes proporções de resíduo úmido de cervejaria sobre o consumo de nutrientes e o ganho de peso de cordeiros terminados em confinamento e realizar uma análise econômica da alimentação oferecida aos animais.

\section{MATERIAL E MÉTODOS}

O trabalho foi realizado nas instalações de ovinocultura de uma propriedade rural situada no município de Capela de Santana, RS. O período experimental estendeu-se de 20 de outubro de 2005 a 4 de janeiro de 2006.

Foram utilizados 25 cordeiros, machos, nãocastrados, da raça Texel, nascidos de parto simples, desmamados aos 69 dias de idade em média. Os animais foram distribuídos aleatoriamente em cinco tratamentos, com cinco repetições cada. Os animais foram confinados em baias individuais, totalmente cobertas, com piso ripado e dimensão de $1,5 \mathrm{~m}^{2}$ por animal. Todas as baias eram providas de comedouros e bebedouros, onde foram fornecidos alimento e água para os animais.

Os tratamentos ( $\mathrm{T}$ ) foram constituídos por diferentes proporções de substituição do alimento concentrado da dieta por resíduo úmido de cervejaria, a saber: $\mathrm{T} 1=0 \%$; T2 $=25 \%$; T3 $=50 \%$; $\mathrm{T} 4=75 \%$ e T5 $=100 \%$ de substituição.

Após o desmame, os cordeiros, mantidos em regime de confinamento, receberam uma dieta composta de feno de Tifton-85 e mistura concentrada na relação volumoso:concentrado de 40:60, com base na matéria seca (MS). O alimento concentrado foi constituído por milho desintegrado, farelo de soja, mistura mineral e resíduo úmido de cervejaria; as proporções variaram de acordo com os tratamentos. As dietas foram formuladas para serem isoprotéicas, baseadas no teor de proteína bruta $(\mathrm{PB})$ do tratamento com maior proporção de resíduo. Na Tab. 1 é apresentada a proporção dos ingredientes utilizados na formulação das dietas e a composição química das dietas experimentais.

$\mathrm{O}$ alimento foi fornecido, ad libitum, duas vezes ao dia, às $7 \mathrm{~h}$ e $30 \mathrm{~min}$ e às $17 \mathrm{~h}$ e $30 \mathrm{~min}$. A quantidade oferecida foi ajustada em função da sobra observada diariamente, que deveria ser de $15 \%$ da quantidade oferecida no dia anterior, de modo a garantir o consumo voluntário máximo dos animais. Nesse sentido, foram realizadas pesagens diárias das sobras e do alimento que seria oferecido pela manhã e à tarde, para cada animal. 
Consumo, ganho de peso e análise econômica...

Tabela 1. Proporção dos ingredientes e composição química das dietas experimentais em termos de matéria seca (MS), proteína bruta (PB), fibra em detergente neutro (FDN), energia líquida (EL), cálcio (Ca) e fósforo $(\mathrm{P})$

\begin{tabular}{|c|c|c|c|c|c|}
\hline & \multicolumn{5}{|c|}{ Proporção de resíduo de cervejaria } \\
\hline & 0 & 25 & 50 & 75 & 100 \\
\hline & \multicolumn{5}{|c|}{ Proporção do ingrediente (\%MS) } \\
\hline Feno de Tifton- 85 & 40 & 40 & 40 & 40 & 40 \\
\hline Milho desintegrado & 30,42 & 22,71 & 15,01 & 7,31 & ----- \\
\hline Farelo de soja & 28,62 & 21,39 & 14,16 & 6,93 & ----- \\
\hline Resíduo de cervejaria & ----- & 15,00 & 30,00 & 45,00 & 59,33 \\
\hline \multirow[t]{2}{*}{ Calcário calcítico } & 0,96 & 0,90 & 0,83 & 0,76 & 0,67 \\
\hline & \multicolumn{5}{|c|}{ Composição química da dieta (\%MS) } \\
\hline MS & 84,15 & 74,34 & 64,52 & 54,70 & 45,32 \\
\hline PB & 17,52 & 17,52 & 17,52 & 17,52 & 17,52 \\
\hline FDN & 29,42 & 36,11 & 42,80 & 49,49 & 54,63 \\
\hline EL (Mcal/kg) & 1,55 & 1,49 & 1,42 & 1,35 & 1,29 \\
\hline $\mathrm{Ca}$ & 0,55 & 0,55 & 0,55 & 0,55 & 0,55 \\
\hline $\mathrm{P}$ & 0,36 & 0,37 & 0,38 & 0,39 & 0,40 \\
\hline
\end{tabular}

O período experimental foi precedido de 14 dias para adaptação dos animais às instalações, alimentação e manejo. $\mathrm{O}$ ensaio de alimentação iniciou-se após a fase de adaptação, estendendose por 77 dias, após o que os cordeiros foram abatidos. Os cordeiros foram pesados no início e no final da fase experimental, após jejum de sólidos e líquidos de 12 horas. Para melhor acompanhamento do desempenho, foram realizadas pesagens intermediárias a cada 14 dias. A última pesagem ocorreu com um intervalo de 21 dias. A cada duas semanas, foram coletadas amostras das sobras $(15 \%$ do peso total) e dos alimentos oferecidos, sendo feitas amostras compostas a cada 28 dias. Essas foram acondicionadas em sacos plásticos identificados e armazenadas em congelador a $-10^{\circ} \mathrm{C}$, para posteriores análises laboratoriais. As análises foram realizadas segundo as metodologias descritas em Silva (1998).

As medidas de controle sanitário foram tomadas no início do período de adaptação, tendo sido realizado controle endoparasitário e vacinação contra carbúnculo sintomático, gangrena gasosa e enterotoxemia. Durante o período experimental, quando necessário, repetiu-se o controle endoparasitário.

Estudaram-se os consumos de matéria seca (MS), matéria orgânica (MO), proteína bruta (PB), extrato etéreo (EE), fibra em detergente neutro (FDN), carboidratos totais (CHT), carboidratos não estruturais (CNE) e de energia líquida (EL), o peso vivo inicial (PI), o peso vivo final (PF), o ganho de peso diário (GMD) e a conversão alimentar (CA).

Para realizar a análise econômica da alimentação oferecida no experimento, foram considerados os preços de mercado obtidos na região do estudo para os ingredientes das rações, para a carcaça e o peso vivo dos cordeiros. De posse do custo de cada ração e do seu consumo, foi calculado o resultado econômico proporcionado por ração. Consideraram-se os seguintes valores: $\mathrm{R} \$$ $3,50 / \mathrm{kg}$ de peso vivo dos cordeiros, $\mathrm{R} \$ 10,00 / \mathrm{kg}$ de carcaça, $\mathrm{R} \$ 0,35 / \mathrm{kg}$ de feno de Tifton-85, $\mathrm{R} \$$ 0,52/ $\mathrm{kg}$ de milho moído, $\mathrm{R} \$ 0,83 / \mathrm{kg}$ de farelo de soja e R\$ 0,07/kg de resíduo úmido de cervejaria.

O delineamento experimental foi o inteiramente ao acaso, com cinco tratamentos e cinco repetições, sendo cada cordeiro considerado uma unidade experimental. Os dados foram submetidos a análises de variância e de regressão, com auxílio do pacote estatístico SAS (User`s..., 1996). Os modelos foram selecionados com base nos coeficientes de determinação e na significância dos coeficientes de regressão, adotando-se o nível de $10 \%$ de probabilidade, utilizando-se o teste F.

\section{RESULTADOS E DISCUSSÃO}

Os valores para os consumos de $\mathrm{MS}, \mathrm{MO}, \mathrm{PB}$, EE, FDN, CHT e CNE - expressos em quilograma por dia $(\mathrm{kg} / \mathrm{dia})$ em porcentagem de peso vivo $(\% \mathrm{PV})$ e em gramas por unidade de tamanho metabólico $\left(\mathrm{g} / \mathrm{kg} \mathrm{PV}^{0,75}\right) \quad$, EL - 
expressa em megacalorias por dia (Mcal/dia), em megacalorias por quilograma de peso vivo (Mcal/kg PV) e em megacalorias por unidade de tamanho metabólico (Mcal/kg $\left.\mathrm{PV}^{0,75}\right)_{-}$, as equações de regressão e os respectivos coeficientes de variação (CV) são apresentados na Tab. 2.

A ingestão de MS é um dos aspectos mais importantes a serem considerados na formulação de dietas para ruminantes, em razão de sua estreita relação com o desempenho produtivo e reprodutivo dos animais, pois é a partir da ingestão de MS que o animal estará consumindo maior ou menor quantidade de nutrientes. São vários os fatores que podem exercer influência sobre a capacidade do animal em consumir alimento, podendo ser fatores inerentes ao próprio animal, ao alimento, ao ambiente e às condições de manejo.

No presente estudo, o consumo de MS, quando expresso em $\mathrm{kg} / \mathrm{dia}$, foi influenciado $(\mathrm{P} \leq 0,05)$ pela proporção de substituição do alimento concentrado por resíduo úmido de cervejaria, isto é, o consumo apresentou comportamento quadrático. $\mathrm{O}$ máximo consumo de MS ocorreu quando se substituiu $31,1 \%$ do alimento concentrado por resíduo úmido de cervejaria, correspondendo ao consumo de $0,654 \mathrm{~kg} / \mathrm{dia}$. Davis et al. (1983), ao trabalharem com bovinos, verificaram diminuição no consumo de MS quando a porcentagem de inclusão de resíduo úmido de cervejaria na dieta foi maior que $40 \%$. Essa tendência foi observada por Véras et al. (2000), que trabalharam com bovinos Nelore não-castrados, alimentados com rações contendo diferentes proporções de concentrado e teores de FDN entre 28,7 e $63,5 \%$, e estimaram o consumo máximo de $8,51 \mathrm{~kg} /$ dia para uma dieta contendo $54,9 \%$ de concentrado e $42,7 \%$ de FDN.

O aumento da proporção de resíduo úmido de cervejaria na dieta acima de $31,1 \%$ proporcionou redução do consumo, o que pode ser explicado pelo aumento do teor de FDN nas dietas, promovendo regulação física do consumo (Fig. 1), confirmando, assim, resultados já obtidos por Kozloski et al. (2006) de que o aumento da proporção de FDN diminui o consumo de alimento por cordeiros confinados. Uma dieta com alta proporção de FDN pode garantir fermentação adequada que proporcione aporte significativo de proteína e outros nutrientes de origem microbiana e, conseqüentemente, reduzir os custos com a alimentação; mas também pode promover restrições no consumo alimentar, em função de sua lenta degradação e baixa taxa de passagem através do rúmen, e limitar a exploração econômica em sistemas de produção mais intensivos se a demanda nutricional for mais elevada. Essa afirmativa está de acordo com Mertens (1994), o qual cita que, ao fornecer dieta com alto conteúdo de FDN para ruminantes, o consumo de alimento ocorre até atingir o nível de capacidade do trato gastrintestinal e, com isso, os animais podem ter seu desempenho produtivo comprometido. Por outro lado, a utilização de dietas com baixo conteúdo de fibra leva a uma regulação fisiológica do consumo devido ao aporte energético das dietas, fato este observado no presente estudo. Freitas et al. (2000) afirmaram que o consumo de MS é influenciado pelo conteúdo de FDN presente nas dietas e que o teor de FDN é um parâmetro para ser utilizado como indicador de consumo de alimentos.

As médias de consumo de MS durante o período experimental encontram-se abaixo daquela recomendada pelo NRC (Nutrient..., 1985) para ovinos da mesma categoria utilizada neste estudo, a qual varia de 1,0 a $1,3 \mathrm{~kg}$ MS/animal/dia. Pilar et al. (1994), ao trabalharem com ovinos, machos castrados, de 12 meses de idade, de cinco genótipos diferentes, Hampshire Down (HD), Texel (T), Corriedale (C), Suffolk x Corriedale (SC) e Ile de France x Corriedale (IC), alimentados durante 80 dias em confinamento com dieta composta por silagem de milho $(60,5 \%$ da $\mathrm{MS})$ e concentrado (39,5\% da MS), observaram consumo diário de MS de $1.093 \mathrm{~g}$ (HD), 828g (T), 874g (C), 924g (SC) e $869 \mathrm{~g}$ (IC). Esses valores foram mais elevados que os encontrados neste experimento e podem ser explicados pela menor idade e pelo menor peso vivo dos cordeiros do presente trabalho.

Ao avaliarem o desempenho de cordeiros Merino Australiano e cruzados Ile de France x Merino Australiano, Pilar et al. (2003) observaram, na fase de crescimento dos 15 aos $25 \mathrm{~kg}$ de peso vivo, consumo de MS (kg/animal/dia) de 732 e $707 \mathrm{~g}$, respectivamente, resultados próximos aos encontrados neste estudo. 
Tabela 2. Valores médios para consumos de matéria seca (CMS), matéria orgânica (CMO), proteína bruta (CPB), extrato etéreo (CEE), fibra em detergente neutro (CFDN), carboidratos totais (CCHT), carboidratos não estruturais (CCNE) e de energia líquida (EL), em função da proporção de substituição do alimento concentrado por resíduo úmido de cervejaria

\begin{tabular}{|c|c|c|c|c|c|c|c|c|}
\hline & \multicolumn{5}{|c|}{ Proporção de resíduo de cervejaria } & \multirow{2}{*}{$\begin{array}{c}\text { Equação de regressão } \\
(\hat{\mathrm{Y}})\end{array}$} & \multirow{2}{*}{$\mathrm{R}^{2}$} & \multirow{2}{*}{$\begin{array}{l}\mathrm{CV} \\
(\%) \\
\end{array}$} \\
\hline & 0 & 25 & 50 & 75 & 100 & & & \\
\hline CMS (kg/dia) & 0,631 & 0,648 & 0,642 & 0,610 & 0,528 & $\begin{array}{l}0,62886+0,00161 * * \text { RES }- \\
0,0000259 * * \mathrm{RES}^{2}\end{array}$ & 0,26 & 11,95 \\
\hline CMO (kg/dia) & 0,591 & 0,606 & 0,603 & 0,575 & 0,501 & $\begin{array}{l}0,58830+0,00149 * * \text { RES }- \\
0,00002341 * * \mathrm{RES}^{2}\end{array}$ & 0,24 & 12,94 \\
\hline CPB (kg/dia) & 0,118 & 0,120 & 0,120 & 0,114 & 0,100 & $\begin{array}{l}0,11782+0,000278 * * \text { RES }- \\
0,00000452 * * \mathrm{RES}^{2}\end{array}$ & 0,26 & 12,38 \\
\hline CEE (kg/dia) & 0,014 & 0,019 & 0,026 & 0,033 & 0,034 & $\begin{array}{l}0,01361+0,00031433 * * * \text { RES }- \\
0,00000107 * * * \mathrm{RES}^{2}\end{array}$ & 0,85 & 13,04 \\
\hline CFDN (kg/dia) & 0,262 & 0,314 & 0,359 & 0,382 & 0,367 & $\begin{array}{l}0,25960+0,00289 * * \mathrm{RES}- \\
0,00001787 * * * \mathrm{RES}^{2}\end{array}$ & 0,52 & 13,46 \\
\hline CCHT (kg/dia) & 0,458 & 0,466 & 0,456 & 0,428 & 0,368 & $0,47782-0,000864 * *$ RES & 0,23 & 13,89 \\
\hline CCNE (kg/dia) & 0,209 & 0,165 & 0,111 & 0,059 & 0,012 & $0,21079-0,00200 * * *$ RES & 0,95 & 14,99 \\
\hline CEL (Mcal/dia) & 1,048 & 1,021 & 0,973 & 0,880 & 0,721 & $1,08650-0,00317 * * * \mathrm{RES}$ & 0,49 & 12,94 \\
\hline CMS (\%PV) & 2,74 & 2,62 & 2,82 & 2,68 & 2,75 & & --- & 12,38 \\
\hline CMO (\%PV) & 2,56 & 2,45 & 2,65 & 2,53 & 2,61 & & ---- & 12,42 \\
\hline $\mathrm{CPB}(\% \mathrm{PV})$ & 0,51 & 0,49 & 0,53 & 0,50 & 0,52 & & ---- & 12,31 \\
\hline CEE (\%PV) & 0,06 & 0,08 & 0,11 & 0,14 & 0,17 & $0,05645+0,00117 * * * \mathrm{RES}$ & 0,86 & 15,26 \\
\hline CFDN (\%PV) & 1,15 & 1,27 & 1,58 & 1,68 & 1,91 & $1,13315+0,00775^{* * *} \mathrm{RES}$ & 0,65 & 13,82 \\
\hline CCHT (\%PV) & 1,99 & 1,88 & 2,00 & 1,88 & 1,92 & 1,94 & ---- & 12,37 \\
\hline CCNE $(\% \mathrm{PV})$ & 0,90 & 0,66 & 0,49 & 0,26 & 0,06 & $0,89325-0,00834 * * * \mathrm{RES}$ & 0,98 & 9,39 \\
\hline CEL (Mcal/kg PV) & 0,045 & 0,041 & 0,043 & 0,039 & 0,037 & $0,04482-0,00007390 * *$ RES & 0,24 & 11,82 \\
\hline $\mathrm{CMS}\left(\mathrm{g} / \mathrm{kg} \mathrm{PV}^{0,75}\right)$ & 59,72 & 58,31 & 61,22 & 58,04 & 57,19 & & --- & 8,79 \\
\hline $\mathrm{CMO}\left(\mathrm{g} / \mathrm{kg} \mathrm{PV} \mathrm{PV}^{0,75}\right)$ & 55,87 & 54,49 & 57,46 & 54,68 & 54,28 & & ---- & 8,79 \\
\hline $\mathrm{CPB}\left(\mathrm{g} / \mathrm{kg} \mathrm{PV}^{0,75}\right)$ & 11,19 & 10,83 & 11,44 & 10,86 & 10,83 & & ---- & 8,35 \\
\hline $\mathrm{CEE}\left(\mathrm{g} / \mathrm{kg} \mathrm{PV}^{0,75}\right)$ & 1,32 & 1,75 & 2,50 & 3,11 & 3,62 & $1,27832+0,02377 * * * \operatorname{RES}$ & 0,93 & 9,70 \\
\hline CFDN $\left(\mathrm{g} / \mathrm{kg} \mathrm{PV}^{0,75}\right)$ & 24,92 & 28,32 & 34,26 & 36,35 & 39,80 & $25,22494+0,15065 * * *$ RES & 0,75 & 9,81 \\
\hline $\mathrm{CCHT}\left(\mathrm{g} / \mathrm{kg} \mathrm{PV}^{0,75}\right)$ & 43,36 & 41,92 & 43,51 & 40,70 & 39,83 & & --- & 8,95 \\
\hline $\mathrm{CCNE}\left(\mathrm{g} / \mathrm{kg} \mathrm{PV}^{0,75}\right)$ & 19,69 & 14,80 & 10,56 & 5,63 & 1,31 & 19,59894-0,18391***RES & 0,99 & 7,53 \\
\hline CEL (Mcal/kg PV $\left.{ }^{0,75}\right)$ & 0,10 & 0,10 & 0,10 & 0,09 & 0,08 & $0,09910-0,00020094 * * *$ RES & 0,51 & 8,20 \\
\hline
\end{tabular}

** e ***: significativo a 5 e $1 \%$ de probabilidade, respectivamente, pelo teste $\mathrm{F}$.

RES = proporção de resíduo úmido de cervejaria da dieta.

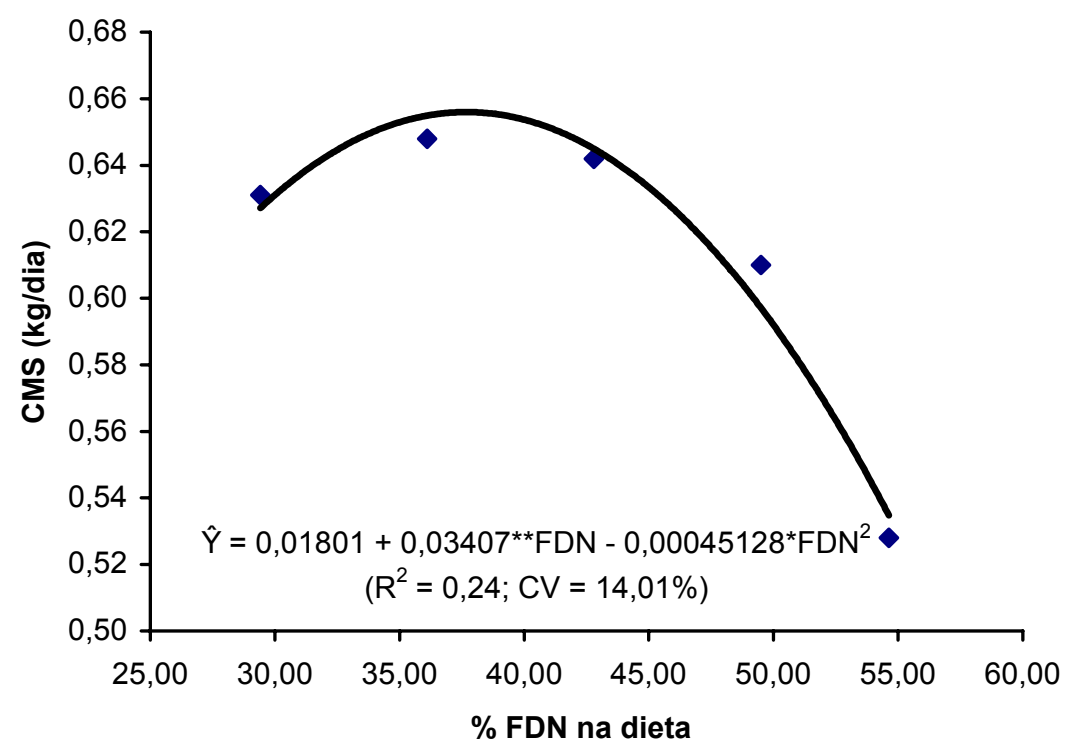

Figura 1. Relação entre o consumo de matéria seca (CMS) e o teor de fibra em detergente neutro (FDN) nas dietas. 
Os consumos de MO, PB e EE, quando expressos em $\mathrm{kg} / \mathrm{dia}$, foram influenciados significativamente pela porcentagem de substituição do alimento concentrado por resíduo úmido de cervejaria, apresentando comportamento quadrático. Estes resultados foram influenciados pelos mesmos padrões de consumo observados para MS e FDN. Os consumos de CHT, CNE e de EL também foram influenciados pela porcentagem de substituição citada, entretanto apresentaram tendência linear decrescente, o que pode ser explicado pela redução na concentração desses nutrientes na dieta com o aumento da proporção de substituição do alimento concentrado por resíduo úmido de cervejaria (Tab. 1).

Quando os valores de consumo de matéria seca foram expressos em percentual $(\% \mathrm{PV})$, não houve diferença entre os tratamentos. O mesmo ocorreu quando o consumo de MS foi expresso em gramas por unidade de tamanho metabólico $\left(\mathrm{g} / \mathrm{kg} \mathrm{PV}^{0,75}\right)$, pois, conforme Pilar et al. (1994), o peso metabólico $\left(\mathrm{PV}^{0,75}\right)$ homogeneiza os animais por área superficial, retirando o efeito de peso vivo.

Os valores médios para PI, PF, GMD e CA são apresentados na Tab. 3.

Tabela 3. Valores médios para peso inicial (PI), peso final (PF), ganho de peso diário (GMD) e conversão alimentar (CA), em função da proporção de substituição do alimento concentrado por resíduo úmido de cervejaria

\begin{tabular}{|c|c|c|c|c|c|c|c|c|}
\hline & \multicolumn{5}{|c|}{ Proporção de resíduo de cervejaria } & \multirow{2}{*}{ Equação de regressão } & \multirow{2}{*}{$\mathrm{R}^{2}$} & \multirow{2}{*}{$\begin{array}{l}\text { CV } \\
(\%)\end{array}$} \\
\hline & 0 & 25 & 50 & 75 & 100 & & & \\
\hline PI (kg) & 16,16 & 16,77 & 15,82 & 15,82 & 14,66 & \multirow{4}{*}{$\begin{array}{c}\hat{\mathrm{Y}}=0,16085- \\
0,00039047 * \mathrm{RES}\end{array}$} & \multirow{4}{*}{0,13} & 23,27 \\
\hline PF (kg) & 28,00 & 28,20 & 26,80 & 28,48 & 22,12 & & & 20,71 \\
\hline $\begin{array}{l}\text { GMD } \\
\text { (kg/dia) }\end{array}$ & 0,153 & 0,148 & 0,142 & 0,164 & 0,097 & & & 26,92 \\
\hline $\mathrm{CA}$ & 4,15 & 4,47 & 4,96 & 3,97 & 5,58 & & & 28,36 \\
\hline
\end{tabular}

*Significativo a $10 \%$ de probabilidade pelo teste $\mathrm{F}$.

RES = proporção de resíduo úmido de cervejaria da dieta.

O GMD diminuiu linearmente $(\mathrm{P} \leq 0,1)$ com o aumento da proporção de substituição do alimento concentrado por resíduo úmido de cervejaria, o que pode ser explicado pela redução no aporte energético das dietas que ocorreu com a elevação da proporção de substituição do concentrado por resíduo úmido de cervejaria e pela redução no consumo de matéria seca e, conseqüentemente, de energia líquida, em Mcal/dia (Tab. 2). Este resultado confirma o obtido por Pires et al. (2006), que trabalharam com 20 cordeiros Ile de France $\mathrm{x}$ Texel, confinados e alimentados com dietas contendo diferentes proporções de FDN $(25 \%, 31 \%, 37 \%$ e 43\%), e observaram que o aumento da proporção de fibra na dieta dos cordeiros reduziu, de forma linear, o ganho de peso diário.

Não houve diferença entre os tratamentos quanto à $\mathrm{CA}$. $\mathrm{O}$ valor médio observado para $\mathrm{CA}$, de 4,63 , é semelhante ao encontrado por Furusho et al. (1997), que trabalharam com cordeiros Santa Inês, confinados durante 50 dias, com peso médio de $15,9 \mathrm{~kg}$ e idade em torno de 110 a 120 dias, recebendo dieta contendo pedúnculo do caju, e observaram CA média de 4,33:1. Tal resultado está próximo, também, daquele obtido por Siqueira et al. (1993), que ao trabalharem com 25 cordeiros, desmamados aos 60 dias de idade e confinados por 91 dias após o desmame, verificaram GMD de 0,153kg e CA de 5,52:1. Deve-se destacar que, conforme Ribeiro (1996), a CA de cordeiros pode ser de 1:1 no período inicial de amamentação, pode baixar para 10:1 no desmame, se eles estiverem em pastagens pobres, na terminação, se forem alimentados com rações de boa qualidade, e pode chegar a $3: 1$. Portanto, os resultados dos trabalhos citados foram confirmados neste experimento, o que resultou em alta taxa de crescimento, aspecto que explica a CA obtida.

Os resultados deste estudo são menores que os obtidos por Carvalho et al. (2005), que trabalharam com proporções de substituição de $0 \%, 33 \%, 66 \%$ e $100 \%$ do alimento concentrado por resíduo úmido de cervejaria, e verificaram valor médio para ganho de peso diário de $0,232 \mathrm{~kg}$ e CA média de $3,46: 1$. Contudo, cabe salientar que esses autores trabalharam com 
silagem de milho como alimento volumoso, na proporção de $50 \%$ da dieta total.

$\mathrm{Na}$ Tab. 4 são apresentados os resultados econômicos do experimento realizado, o qual visou avaliar apenas a viabilidade econômica da substituição do alimento concentrado por resíduo úmido de cervejaria na alimentação dos cordeiros.

Tabela 4. Valores médios para peso vivo final (PF), peso de carcaça fria (PCF), oferecido matéria natural de feno (OFMNF), oferecido matéria natural de concentrado (OFMNC), oferecido matéria natural de resíduo úmido de cervejaria (OFMNR), custo diário de feno $(\mathrm{CDF})$, custo diário de concentrado $(\mathrm{CCD})$, custo diário de resíduo úmido de cervejaria (CRD), custo diário total (CDT), custo total (CT), receita do peso vivo (RPV), receita de carcaça (RC), lucro de peso vivo (LPV) e lucro de carcaça (LC), em função da proporção de substituição do alimento concentrado por resíduo úmido de cervejaria

\begin{tabular}{|c|c|c|c|c|c|c|c|c|}
\hline & \multicolumn{5}{|c|}{ Proporção de resíduo de cervejaria } & \multirow{2}{*}{$\begin{array}{c}\text { Equação de regressão } \\
(\hat{Y})\end{array}$} & \multirow{2}{*}{$\mathrm{R}^{2}$} & \multirow{2}{*}{$\begin{array}{l}\mathrm{CV} \\
(\%)\end{array}$} \\
\hline & 0 & 25 & 50 & 75 & 100 & & & \\
\hline PF (kg) & 28,00 & 28,20 & 26,80 & 28,48 & 22,12 & & ---- & 20,71 \\
\hline $\mathrm{PCF}(\mathrm{kg})$ & 12,98 & 13,22 & 11,98 & 12,42 & 8,92 & $13,65020-0,03531 * *$ RES & 0,19 & 23,29 \\
\hline OFMNF (kg/dia) & 0,387 & 0,390 & 0,402 & 0,390 & 0,341 & $\begin{array}{l}0,38308+0,00109 * \text { RES- } \\
0,00001470 * \mathrm{RES}^{2}\end{array}$ & 0,20 & 12,03 \\
\hline OFMNC (kg/dia) & 0,542 & 0,410 & 0,281 & 0,136 & 0,0 & $0,54524-0,00543 * * * \operatorname{RES}$ & 0,96 & 15,16 \\
\hline OFMNR (kg/dia) & 0,0 & 0,506 & 1,049 & 1,515 & 1,749 & $0,06292+0,01802 * * * \mathrm{RES}$ & 0,95 & 15,67 \\
\hline CDF (R\$/animal/dia) & 0,14 & 0,14 & 0,14 & 0,14 & 0,12 & & ---- & 11,99 \\
\hline CCD (R\$/animal/dia) & 0,36 & 0,27 & 0,18 & 0,09 & 0,0 & $0,35923-0,00359 * * * \mathrm{RES}$ & 0,96 & 15,23 \\
\hline CRD (R\$/animal/dia) & 0,0 & 0,03 & 0,07 & 0,10 & 0,12 & $0,00444+0,00124 * * *$ RES & 0,95 & 15,81 \\
\hline CDT (R\$/animal/dia) & 0,49 & 0,44 & 0,40 & 0,33 & 0,24 & $0,50382-0,00248 * * *$ RES & 0,80 & 12,33 \\
\hline $\mathrm{CT}(\mathrm{R} \$)$ & 37,96 & 34,07 & 30,45 & 25,23 & 18,49 & 38,79269-0,19108***RES & 0,80 & 12,35 \\
\hline RPV (R\$/animal) & 98,00 & 98,70 & 93,80 & 99,68 & 77,42 & & ---- & 20,72 \\
\hline $\mathrm{RC}$ (R\$/animal) & 129,77 & 132,19 & 119,74 & 124,16 & 89,20 & $136,48251-0,35305 * *$ RES & 0,19 & 23,29 \\
\hline LPV (R\$/animal) & 60,04 & 64,62 & 63,35 & 74,45 & 58,93 & & --- & 25,05 \\
\hline LC (R\$/animal) & 91,81 & 98,11 & 89,29 & 98,93 & 70,71 & & ---- & 28,16 \\
\hline
\end{tabular}

*,** e ***: significativo a 10,5 e $1 \%$ de probabilidade, respectivamente, pelo teste $\mathrm{F}$.

RES = proporção de resíduo úmido de cervejaria da dieta.

Com relação aos alimentos oferecidos, o feno apresentou comportamento quadrático, o concentrado apresentou tendência linear decrescente e o resíduo apresentou tendência linear crescente, conforme o aumento da proporção de substituição do alimento concentrado por resíduo úmido de cervejaria. Como conseqüência, o custo diário do feno não diferiu significativamente entre tratamentos, contudo os custos diário e total com alimentação decresceram com a substituição.

Em função da não diferença no PF $(26,66 \mathrm{~kg})$, a receita bruta relacionada à venda dos cordeiros vivos também não diferiu entre os tratamentos (R\$ 93,30 em média). A receita bruta em relação ao peso de carcaça diminui linearmente com a elevação do teor de resíduo úmido de cervejaria na dieta, como conseqüência da redução do peso de carcaça fria. Entretanto, quando se desconta da receita bruta a despesa total com alimentação (feno + concentrado + resíduo), verifica-se que, devido à diminuição do custo de alimentação com a elevação do teor de resíduo úmido de cervejaria, quando se avaliou a lucratividade com relação à venda dos cordeiros vivos e das carcaças, não houve efeito significativo de tratamento, tendo sido encontrado um valor médio para lucratividade do peso vivo e da carcaça de R\$ 64,26 e R\$ 89,42, respectivamente.

\section{CONCLUSÕES}

O aproveitamento do resíduo úmido de cervejaria na alimentação de cordeiros em sistema se confinamento é uma alternativa para destinação adequada desse resíduo. Recomenda-se que a proporção máxima de substituição do alimento concentrado por resíduo úmido de cervejaria seja de $31,1 \%$.

\section{REFERÊNCIAS BIBLIOGRÁFICAS}

CAMPOS, W.E.; BORGES, A.L.C.C.; SATURNINO, H.M. et al. Degradabilidade ruminal das frações do resíduo industrial de tomate. Arq. Bras. Med. Vet. Zootec., v.59, p.189-195, 2007.

CARVALHO, S.; PIVATO, J.; KIELING, R. et al. Níveis de inclusão de resíduo de cervejaria na 
alimentação de cordeiros. In: REUNIÃO ANUAL DA SOCIEDADE BRASILEIRA DE ZOOTECNIA, 42., 2005, Goiânia. Anais... Goiânia: SBZ, 2005. CD-ROM.

DAVIS，C.L.; GRENAWALT, D.A.; McCOY, G.C. Feeding value of pressed brewers' grains for lactating dairy cows. J. Dairy Sci., v.66, p.73-79, 1983.

FREITAS, T.S.; PRATES, E.R.; BARCELLOS, J.O.J. et al. Relação entre o consumo por ovinos de gramíneas e leguminosas com o conteúdo de FDN. In: REUNIÃO DA SOCIEDADE BRASILEIRA DE ZOOTECNIA, 27., 2000, Viçosa. Anais... Viçosa: SBZ, 2000. CD-ROOM.

FURUSHO, I.F.; PÉREZ, J.R.O.; LIMA, G.F.C. et al. Desempenho de cordeiros Santa Inês, terminados em confinamento, com dieta contendo pedúnculo do caju. Disponível em: $<$ http://www.sbz.org.br/anais1997/nru/bnru271.pdf/ >. Acessado em: 12 dez. 2006.

KOZLOSKI, G.V.; TREVISAN, L.M.; BONNECARRÈRE, L.M. et al. Níveis de fibra em detergente neutro na dieta de cordeiros: consumo, digestibilidade e fermentação ruminal. Arq. Bras. Med. Vet. Zootec., v.58, p.893-900, 2006.

MERTENS, D.R. Regulation of forage intake. In: FAHEY Jr., G.C. (Ed). Forage quality, evaluation and utilization. Madison: American Society of Agronomy, 1994. p.450-493.

NUTRIENT requirements of sheep. 6.ed. Washington: National Academy of Sciences, 1985. $242 p$.

OLIVEIRA, M.V.M.; PÉREZ, J.R.O.; ALVES, E.L. et al. Avaliação da composição de cortes comerciais, componentes corporais e órgãos internos de cordeiros confinados e alimentados com dejetos de suínos. Rev. Bras. Zootec., v.31, supl., p.1459-1468, 2002.

PILAR, R.C.; PIRES, C.C.; RESTLE, J. et al. Desempenho em confinamento e componentes do peso vivo de diferentes genótipos de ovinos abatidos aos doze meses de idade. Cienc. Rural, v.24, p.607-612, 1994.

PILAR, R.C.; PÉREZ, J.R.O.; TEIXEIRA, J.C. et al. Desempenho de cordeiros Merino Australiano e cruzados Ile de France x Merino Australiano. Cienc. Agrotecnol., edição especial, p.1652-1661, 2003.

PIRES, C.C.; SILVA, L.F.; SCHLICK, F.E. et al. Cria e terminação de cordeiros confinados. Cienc. Rural, v.30, p.875-880, 2000.

PIRES, C.C.; GALVANI, D.B.; CARVALHO, S. et al. Características da carcaça de cordeiros alimentados com dietas contendo diferentes níveis de fibra em detergente neutro. Rev. Bras. Zootec., v.35, p.2058-2065, 2006.

RIBEIRO, L.A.O. Sobrevivência e desempenho de cordeiros do período perinatal ao desmame. In: SENAR. Programa de Treinamento em Ovinocultura. Porto Alegre: FARSUL/SENAR, 1996. $100 \mathrm{p}$

ROGÉRIO, M.C.P.; BORGES, I.; NEIVA, J.N.M. et al. Valor nutritivo do resíduo da indústria processadora de abacaxi (Ananas comosus L.) em dietas para ovinos.1. Consumo, digestibilidade aparente e balanços energético e nitrogenado. Arq. Bras. Med. Vet. Zootec., v.59, p.773-781, 2007.

SACHS, I. Resíduos sólidos: Ignacy Sachs faz defesa da valorização. Rev. San. Amb., n.112, p.68,2005 .

SIQUEIRA, E.R.; AMARANTE, A.F.T.; FERNANDES, S. Estudo comparativo da recria de cordeiros em confinamento e pastagem. Rev. Vet. Zootec., v.5, p.17-28, 1993.

SILVA, D.J. Análise de alimentos: métodos químicos e biológicos. Viçosa: UFV, 1998. 165p.

SILVA FILHO, J.C.; ARMELIN, M.J.A.; SILVA, A.G. Determinação da composição mineral de subprodutos agroindustriais utilizados na alimentação animal pela técnica de ativação neutrônica. Pesq. Agropec. Bras., v.34, p.235-241, 1999.

USER'S guide: statistical analysis system. Realese 6.11. Cary, NC: SAS Institute, 1996.

VÉRAS, A.S.C.; VALADARES FILHO, S.C.; SILVA, J.F.C. et al. Consumo e digestibilidade aparente em bovinos Nelore, não-castrados, alimentados com rações contendo diferentes níveis de concentrado. Rev. Bras. Zootec., v.29, supl.2, p.2367-2378, 2000. 